\title{
Netflix Comes to the Nordics: Lessons in OTT Video
}

\author{
Roslyn Layton \\ Center for Communication Media and Information Studies, \\ Aalborg University, Denmark
}

Received: July 2013; Accepted: September 2013

\section{Introduction/Abstract}

Netflix is the world's leading provider of subscription-based over the top (OTT) streaming video, television, and movies delivered over the internet to over 30 million subscribers in 40 countries generating USD $\$ 2.5$ billion in video streaming revenue annually. ${ }^{1}$ When Netflix launched in the Nordic countries in Q4 2012, the Nordic press called it a major threat to incumbent pay TV provided. They suggested that consumers would give up their current pay TV subscriptions for linear or flow TV and switch to Netflix. A number of stories appeared about Netflix in a tete-a-tete with DSL providers, as the OTT service is growing to account for the majority of traffic on copper networks and the company's public relations practices.

As we watch the situation unfold in Denmark, Norway and Sweden, we can see that the reality of television is not changing overnight, but that it's evolving. Netflix and its OTT video competitors such as HBO Nordic have a number of challenges. Established players such as Danish YouSee, Telenor Norway and Sweden's Viasat and Com Hem are making competitive responses. YouSee has suggested it will offer its cable channels in an a la carte fashion in 2014. Consumers, while intrigued by the growing possibilities, don't necessarily switch to new services instantly, but free trials are certainly popular. In any

\footnotetext{
${ }^{1}$ http://files.shareholder.com/downloads/NFLX/2273280957x0x630302/e7656660-df354384-9f39-cb0f39e54f0b/Investor\%20Letter\%20Q42012\%2001.23.13.pdf
}

Journal of NBICT, Vol. 1, 109-138.

doi: 10.13052/NBICT.2015.005

(C) 2015 River Publishers. All rights reserved. 
case, a number of have complained that Netflix does not meet its expectations for content.

OTT video today is equal to but $2 \%$ of the $\$ 300$ billion pay TV market. While there is scant academic literature on the topic of OTT video, there are a number of commercial and financial reports, many touting that OTT video as the new paradigm for television. The academic basis for understanding OTT video comes from fields such as disruptive innovation, evolutionary economics and network/telecom engineering. Therefore we believe a review of OTT video from an academic perspective can inform the understanding of the new phenomenon. Looking at the advent of American OTT players to Europe offers an opportunity to review the conventional economic theory about internet business models as well as whether the Nordic case can inform larger questions about digital globalization.

This article provides a summary of the key lessons about OTT video by looking at the experience of Netflix in the Nordic region. It discusses the role of the content market, the ongoing need for connectivity, and the strengths and weaknesses of existing media and telecom companies in the region. It also addresses some the corporate practices of Netflix and policy issues which the company has forced by entering the region. To support our investigation, we include some information from Danske Bank, the leading financial institution in Denmark covering the internet/telecom sectors. We conclude that OTT video represents an important evolutionary development, but not the overnight disruption as painted by the commercial press. Without a doubt, OTT video creates competition that lowers prices.

Even if consumers don't purchase an OTT video, technologies such as Netflix condition consumers to new desires and behaviors which will be absorbed by traditional providers and productized in their new offerings. Consumers desire to watch content at their leisure, not on the fixed time schedule of the broadcaster. They also want more ability to pick and choose from an a la carte menu of video options. Thus we will see traditional pay TV providers with their own on demand services as well as more ability to purchase content in a piecemeal fashion, instead of the traditional bundle.

\section{What Is OTT Video?}

Over the top (OTT) video is television or film that is consumed from the internet. It is a type of Internet protocol television (IPTV) delivered over a packet-switched network with higher standards than ordinary internet video. 
OTT video, a subject of IPTV, is based on hypertext transfer protocol (HTTP) and lives "on top" of a data network. Traditional terrestrial television is transmitted through the air via radio waves to a classic television. Satellite TV is transmitted via signal from an orbiting device in space, received by an antenna mounted on the home and connected to a set top box or tuner. Conventional cable TV is transmitted via a coaxial or fiber optic cable into a set top box. Viewing OTT video generally requires a digital terminating device and an internet subscription.

Overall IPTV options include live TV, time-shifted TV and video on demand (of which OTT video is a subset), and the market is more than \$22 billion globally. While broadcast TV sends a constant flow of content to the end user, IPTV allows the user to regulate his consumption based upon individual preferences and to freeing bandwidth to other uses. IPTV can be converged with other IP services such as voice, SMS, data and so on. Leading providers include Deutsche Telekom in Germany, Free in France, Korea Telecom and AT\&T in the USA. While it is not true in every instance, in practical terms a network carrier/operator provides IPTV via DSL as one of the suite of products of its network offering (which it monetizes) while an OTT video provider offers a service on top of the network (which competes with existing network services for bandwidth and share of wallet). In this way, OTT video is a classic example of co-opetition, when two competing parties act with partial interest. Their cooperation creates higher value for the system, but each party competes for an advantage.

OTT video is an important phenomenon for a number of reasons. OTT video allows people to watch film and television when it suits them, not at the defined time by a broadcaster. One can watch an entire series at once or in any increments, something impossible on linear TV. From an innovation and competition perspective, OTT opens up the world of TV and movies to new and different players, though albeit not with the same economic returns. It offers content discovery and personalization tools (algorithms to help the user find interesting content), digital libraries (a user's content stored in the cloud can be accessed anywhere), encryption for digital rights management (a film that is rented for 24 hours becomes unavailable after the defined period), and audience measurement (digital platforms enable immediate analytics about user behavior; traditional media need to employ offline third party measurement, e.g. Gallup or Nielsen). OTT video is emboldened further by a proliferation of content and consumer electronics devices, and Netflix, given its scale, is able to partner and experiment with device companies to innovate internet video consumption. 
It is also important to make the following distinctions. Pay per view (PPV) is television offered on a fixed time basis for a fee. This is frequently an option available for sporting events, but also for some films. There is also video on demand (VOD), pre-recorded video stored on a server which the viewer watches at his leisure. Finally streaming video on demand (SVOD) is video received in a constant flow, so the user can watch immediately. Downloadable video must first be "downloaded" before it can be watched.

Here is an overview of the value chain.

\begin{tabular}{|c|c|c|c|c|c|c|c|c|}
\hline \multirow{2}{*}{$\begin{array}{l}\begin{array}{l}\text { Content } \\
\text { Market }\end{array} \\
\text { Content } \\
\text { Creators }\end{array}$} & \multicolumn{6}{|c|}{$\begin{array}{c}\text { Distribution } \\
\text { Networks }\end{array}$} & Devices/Apps & Consumers \\
\hline & $\begin{array}{c}\text { Film } \\
\text { Studios }\end{array}$ & $\begin{array}{l}\text { Terrestrial } \\
\text { TV/DVB-T }\end{array}$ & Satellite & Cable & DSL & Fiber & \multirow{4}{*}{$\begin{array}{c}\text { Television } \\
\text { Set Top Boxes } \\
\text { Smart TVs } \\
\text { Tablets } \\
\text { Game Consoles } \\
\text { Smartphones }\end{array}$} & \multirow{4}{*}{$\begin{array}{l}\text { TV License Fee } \\
\text { DVDs } \\
\text { Cable } \\
\text { subscription } \\
\text { Internet } \\
\text { Subscription }\end{array}$} \\
\hline Content & \multirow{2}{*}{$\begin{array}{c}\text { Cinemas } \\
\text { DVDs }\end{array}$} & \multirow{2}{*}{$\begin{array}{c}\text { Broadcaster } \\
\text { s }\end{array}$} & & \multicolumn{3}{|c|}{ Internet } & & \\
\hline $\begin{array}{c}\text { Owners } \\
\text { Content } \\
\text { Aggregators }\end{array}$ & & & & \multicolumn{3}{|c|}{$\begin{array}{l}\text { OTT Video } \\
\text { Broadcasters }\end{array}$} & & \\
\hline $\begin{array}{l}\text { (actors, film } \\
\text { studios, } \\
\text { production } \\
\text { companies } \\
\text { etc) } \\
\text { Governed by } \\
\text { IPR }\end{array}$ & & & & & & & & \\
\hline
\end{tabular}

\section{Netflix and Challenges to Grow OTT Video}

It's no surprise that Netflix should love Denmark, and the Nordics for that matter. The region is home to 25 million consumers with relatively high broadband penetration and income. While American film and television has a global audience, the fact that English is widely spoken in the Nordic region as has advantages for repurposing content from the US and UK markets. As an indication of its enthusiasm, the Netflix Q4 earning reports notes an investment of \$105 million in marketing (largely for the Nordic launch), the rollout was called the best of its international expansion to date. ${ }^{2}$

Netflix's roots are in the DVD by mail business, which it began in 1997. Ten years later it had 100,000 DVD titles and surpassed 10 million subscribers. It would not be an exaggeration to say that Netflix helped destroy Blockbuster with lower overhead and more intelligent matching of content to consumers. The DVD by mail model allowed wider distribution at a lower cost (no need for brick and mortar store), as well as more favorable pricing with lower late fees. Once the world's largest chain of video rental stores with

\footnotetext{
${ }^{2}$ http://www.dagensit.no/article2544378.ece
} 
60,000 employees, Blockbuster filed for bankruptcy in 2010 and was acquired by the Dish Network, a satellite television company. As the last of Blockbuster stores have closed, they earned a greater margin on Ben \& Jerry's ice cream rather than the videos themselves.

The Netflix company folklore holds that CEO Reed Hastings was annoyed about a $\$ 40$ late fee for a DVD rental of "Apollo 13" and launched the company. ${ }^{3}$ Just two years later, Netflix began its OTT video service in the US. Today Netflix accounts for more data traffic in the USA than any other website. According to a 2012 report by internet measurement company Sandvine, Netflix is the biggest source of North American web traffic, accounting for $33 \%$ of bandwidth on wire line networks. ${ }^{4}$

Netflix started internationalization in late 2010 in Canada. The following year it went to Latin America. 2012 has seen the addition of UK and Ireland in the beginning of the year, followed by the Nordics at the end of the year. Netflix head of Global Communications Joris Evers noted, "Denmark and the Nordic region are perhaps our best release so far. Should I judge from our experience in Canada, we can easily end up that one in five Danish broadband connected households have Netflix within a few years." ${ }^{5}$ In Denmark Netflix offers a free month trial and then a monthly subscription with unlimited content for 79 DDK, less than a price for a movie ticket.

\section{Scale: What It Costs to Acquire a Customer}

Netflix is not an overnight success by any means. It took the company 6 years to turn its first profit. After the IPO in 2002, Netflix reported its first net positive income in the following year, \$6.5 million net revenue on \$272 million in total revenue. The company has grown considerably since then, closing 2012 with $\$ 3.6$ billion in total revenue. Today the profit margin of the company's DVD by mail business is two-four times (depending on the quarter) as profitable as streaming video, but like many innovative companies, Netflix realized that it had to "kill its darling" to take advantage of the internet.

Another evolution that speaks to internet technology and economies of scale is Netflix declining customer acquisition cost. When it began, Netflix had to pay well over $\$ 100$ to acquire a customer. That figure has since plummeted to less than $\$ 20$ (no doubt helped by free trials). While the total number of subscribers has grown, the revenue per subscriber has decreased over time.

\footnotetext{
${ }^{3}$ http://money.cnn.com/2009/01/27/news/newsmakers/hastings_netflix.fortune/

${ }^{4} \mathrm{http} / / / \mathrm{www}$. sandvine.com/news/global_broadband_trends.asp

${ }^{5} \mathrm{http} / / /$ www.business.dk/digital/netflix-vi-kan-tage-20-procent-af-danmark
} 
For its American customers, it earns about $\$ 8.50$ per month, and the average customer uses the service for about 2 years, so lifetime revenue per customer is slightly more than $\$ 200$.

Netflix's domestic streaming market provides a $16 \%$ profit margin, but international streaming has yet to break even because of high marketing costs. At the close of 2012, Netflix earned $\$ 287,542$ million on its international streaming business, but ran a loss of $\$ 389,311$ million with significant investment costs for content and marketing. However Netflix is banking on the idea that once it acquires customers, its marketing costs will decrease and profitability will improve. ${ }^{6}$

\section{Content: The Two-Sided Coin for Netflix}

While audiences were keen to give Netflix a free trial, after a time, some started to complain that the range of content is limited and outdated. Content licensing fees, even more than technology development, is the ongoing cost driver of Netflix business. The company has some 250 employed in content negotiation, some $20 \%$ of headcount. Incumbent competitors have a head start in content distribution rights, and it will take Netflix at least 2-3 years to get the chance to negotiate agreements for fresh films. Intellectual property rights (IPR) are restricted to specific distributors, by time, and by geography. It is for this reason that Nordic incumbents have a "lock-in" on content and to some extent market power to keep subscribers.

The American portion of Netflix's business is cash positive, supporting its international rollout. While there is significant up-front investment in sales and marketing, Netflix is confident that international revenues will cover international operations after a period of time. What is not clear is to what extent Netflix can compete with the moneyed incumbents to purchase the rights to content internationally. It is not just any content that will suffice. Quality content is important.

Netflix notes that of the top 100 TV shows and top 100 movies (by popularity) in the US, slightly more than $50 \%$ are exclusive to Netflix and not available to competitors Amazon, Hulu, or Redbox. Netflix notes that it also offers movies from one to fifty years old; prior seasons of current TV shows, and complete prior seasons of off-air TV shows. Netflix has exclusive original series which are released on the same day globally, something not seen in the film and television industry before. Some two-thirds of Netflix

\footnotetext{
${ }^{6}$ http://files.shareholder.com/downloads/NFLX/2273280957x0x630302/e7656660-df354384-9f39-cb0f39e54f0b/Investor\%20Letter\%20Q42012\%2001.23.13.pdf
} 
content is television shows, and the company intends to continue differentiating in that vein, with the goal to launch at one new original series per month.

Netflix maintains that exclusive and original content are how each pay TV provider will differentiate in the future, and that consumers will choose a range of options for entertainment, news and sports including a basic cable package with a set of OTT video options for specialized content.

It is worth noting that Netflix is an OTT video subscription service, but Amazon and AppleTV are catalog based services, where the user makes single purchases of content. Hulu is a subscription plus advertising service for the NBC broadcast network and is not available outside the USA. Amazon and AppleTV have localized versions for video content in the Nordics.

\section{The Content Market: Windows to Buy Film and Television Rights}

There is consider delay from the time a film or series is released to when it can be purchased by third parties for redistribution. Film and television studios need time to recoup their investment, and the intellectual property regime allows them initial exclusivity with licensing privileges over years. Content rights are sold through various windows. Film has a longer licensing path than television.

Films first appear in the cinema, called the first window. In the second window, physical DVDs and pay per view are available. After about a year from the release of the film, the third window becomes available. The third window is divided into two sub-windows, first pay (Pay 1) and second pay. In the first pay section, a buyer is allowed exclusivity to distribute the film for one year in a given geography. In the second pay section, another buyer is allowed the privilege. The Pay 1 window is dominated by incumbent cable players with larger cash flows and audiences, and thus, OTT video providers have had difficulty breaking in because of the high cost.

Netflix has Pay 1 for the Nordics with Warner Bros., the world's largest TV producer, and it has just announced Pay 1 for The Walt Disney Studios for American distribution in 2016. As for the Nordic market, Netflix will have to wait until 2015 for its next Pay 1 opportunity.

In the fourth window, about three years after the film's premiere, it is available on regular television where it may reside for 2-3 years. Finally in the fifth window, some 6 years after the film was released, it enters the 
"back catalog" where it is open to all parties for purchase. ${ }^{7}$ This window is the natural, economical entry point for most OTT video providers.

The TV content market runs more quickly. When show is aired on a traditional television network, it is paid immediately from advertisers or from the ongoing revenue streams from a tax on citizens. Then the program goes to cable. Thereafter the show goes to DVD. Finally in about year three, it is available to OTT video players. High quality and specialized television shows are gaining popularity over feature films in the OTT video market. Further, a full season of episodes has a higher purchase price than a single movie.

Here is a diagram of the pay windows, courtesy of Danske Bank Markets.

Here is a diagram of the pay windows, courtesy of Danske Bank Markets.

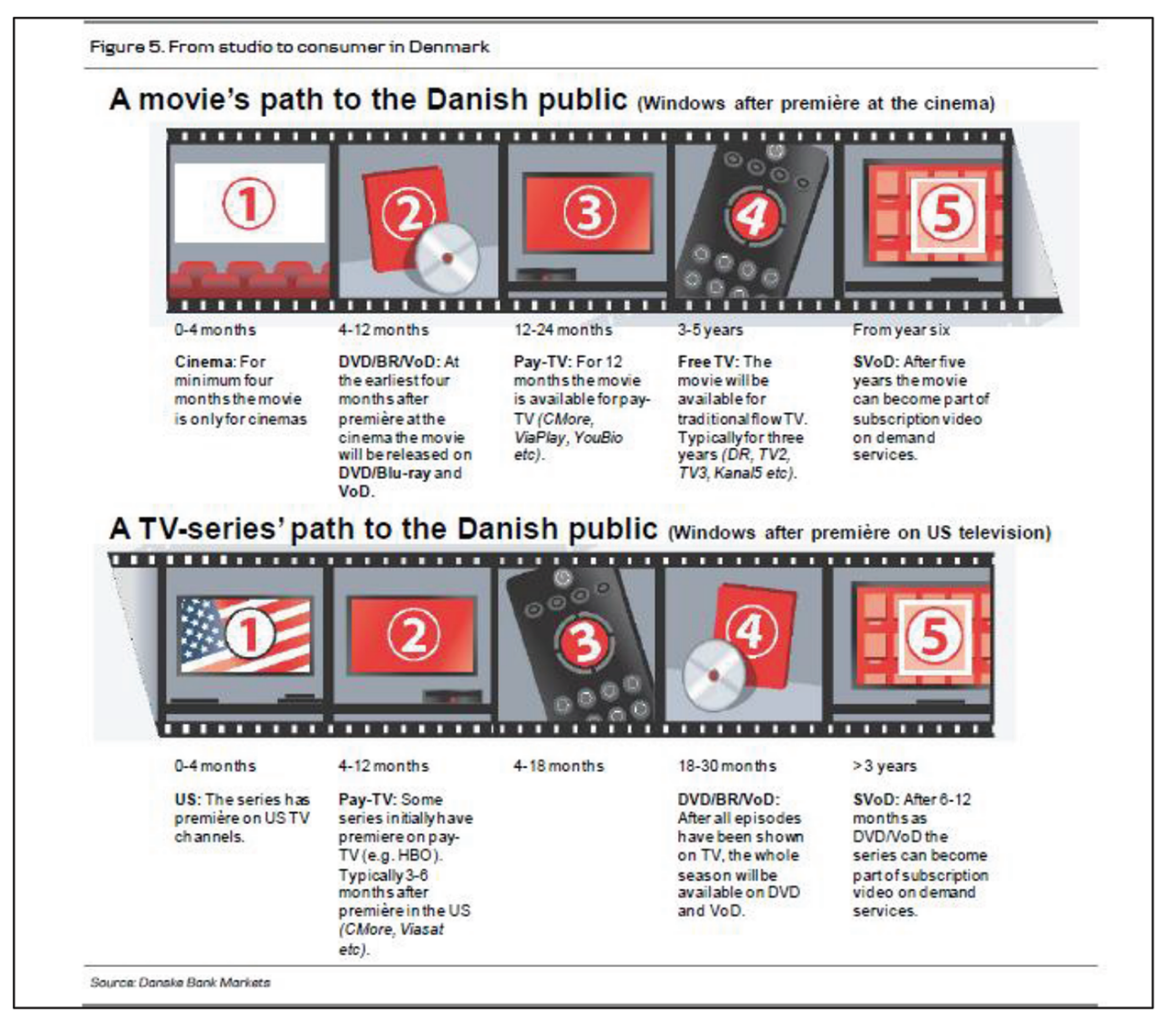

\footnotetext{
${ }^{7}$ https://danske.eu.bdvision.ipreo.com/NSightWeb_v2.00/Handlers/Document.ashx?i=71b6 025c9bf44f189b5985ca4a29d949
} 


\section{The Market for TV and Film in Denmark}

To understand the Nordic market, we use data from Danske Bank Markets which has a department focused on collection of financial information for telecom and internet industries. It estimates the total market for film and television in Denmark to be about DKK7.5 billion (USD \$1.3 billion or $€ 1$ billion Euro). Of this, two thirds (DKK5 billion) is broadcasting/pay TV/cable with the remaining going for cinemas, VOD, and sales of physical DVDs.

Of non-television third of the revenue, DVDs make up 19\% and cinemas $10 \%$. The current portion of $\mathrm{VoD}$ is just $2 \%$, about $\$ 25$ million, half of which belongs to TDC under the YouSee brand. The immediately addressable market for a new OTT video entrant such as Netflix is the current VOD revenue plus the physical sales of DVDs (about 1.6B DKK). Here is a summary.

\begin{tabular}{|lrlrl|}
\hline & $\%$ & DKK & & USD \\
VOD & $2 \%$ & kr. & $150.000 .000,00$ & $\$ 25.500 .000,00$ \\
Cinema & $10 \%$ & kr. & $750.000 .000,00$ & $\$ 127.500 .000,00$ \\
Physical Sales & $19 \%$ & kr. & $1.425 .000 .000,00$ & $\$ 242.250 .000,00$ \\
& $31 \%$ & kr. & $2.325 .000 .000,00$ & $\$ 395.250 .000,00$ \\
\hline
\end{tabular}

Source: Danske Bank Markets, 2012

Cinema in Denmark is dominated by the Danish cinema company Nordisk Film (part of a larger media conglomerate Egmont). This portion is less likely to be affected by OTT video, as consumers continue to demand first run films, especially for 3-D and other blockbusters.

The traditional Danish television broadcasters (DR and TV2) offer a service comprised of news, sports, and entertainment. Neither Netflix nor any current OTT video provider is a threat from the perspective of national news. Danes continue to demand Danish-language news from trusted sources. Danish youngsters read fewer newspapers, but they still watch Danish news, often via the broadcasters' streaming services. The leading sporting events (European and World Cup Football, handball and so on) are already under contract with incumbent broadcasters. Entertainment is the one area where Netflix competes, and it offers a limited range of Danish content. Some $83 \%$ of all viewing in Denmark is in the Danish language. Furthermore traditional TV networks have started to air talent competitions and dance and singing contests which requires viewers to tune in to see who wins.

It is for these reasons that the arrival of OTT video doesn't spell the end of traditional pay TV. In fact Danske Bank expects that in 5 years, the leading TV and cable networks will still have $80-90 \%$ of the revenues they have today. 
This is assured largely by the existing scale of the subscriber base as well as the local content advantage. Furthermore, a government tax assured levied on every household twice a year assures revenue for public broadcasters.

To be sure, OTT video has a disciplining effect on the market and will create price pressure and competition. A key target for OTT is the cable industry with a business model that has been called "extortion" by detractors. A consumer is required to buy a package of channels, even when he may only want just one or two stations. It is in this way that Netflix sees itself as providing a programmatic and curatorial advantage over cable networks, which it views as merely "distributors".

Indeed not all content is created equal. Content such as an HBO original series or a major sporting event demands higher fees than the sundry range of stations for home and garden, fishing, and the like. Thus HBO has used its creation of an OTT video service as a bargaining chip to increase its margin with cable companies. Cable companies need a defensive strategy to offer a range of content at a competitive price and to thwart the defection of customers to specialized OTT video services.

\section{Overview of Key Nordic Players: TV and Connectivity Providers}

A number of the pay TV providers in the Nordic region operate across Denmark, Sweden and Norway but with localization strategies including specialized channels and local language programming. There may be a dozen providers in each country, but we discuss select market leaders for each of the networks: cable, DSL, satellite, fiber, and DVB-T. Mobile broadband subscriptions have grown steadily in recent years, but we considered them additions, not necessarily substitutions, to wire line and satellite access. To be sure, 4G networks can accommodate OTT video, but limited mobile infrastructure will constrains the capacity of this network, and streaming video requires an adequate smartphone. Most $4 \mathrm{G}$ users will have either a cable/copper subscription for OTT video. For an OTT video provider, markets with significant broadband penetration are preferable, if not requisite.

\section{Cable: The Current Content King \\ YouSee/YouBio Denmark}

Coaxial cable is available to at least $60 \%$ of households in Denmark. Notwithstanding the advent of OTT, the economics of cable have been favorable. 
There are a fixed number of households, and cable companies have added channels to each of their packages with a commensurate increase in price. Cable companies have scale through their capital and subscribers to develop long-term relationships with content owners.

The leading cable TV provider in Denmark is YouSee. It is owned by TDC, Denmark's largest telecom operator, and has 58\% of the market for cable in Denmark. It is worthy to note that it is one cable company that was not forced to decouple from the telecom operator, as has been the situation in most European countries. In any case, YouSee has been a successful company, with over 46 quarters of increasing profitability. CEO Niels Breining who has been at the helm for this period and promises to step down once 50 consecutive profitable quarters have been achieved.

YouSee offers its customers monthly subscriptions between DKK209-459 (USD \$37-87). This includes the national Danish television channels (DR1, DR2, TV2, TV3) plus a selection of foreign and domestic content. Customers can have cable package and internet access for 459-708DKK (\$87-127).

Much of the business success of YouSee can be attributed to content, which account for $71 \%$ of the company's revenue. YouSee, in partnership with C More (owned by Swedish media company Bonnier), is a major content buyer in the Danish market. It is able to win favorable pricing for licensing not only with Danish content developers (Nordisk Film) but also with major international film studios that want the best entry into the Danish market. YouBio has Pay 1 with $20^{\text {th }}$, Paramount, MGM, and Dreamworks.

At first blush it would seem that Netflix with its free one-month trial and monthly price of 79 DDK (USD\$13.75) would be a competitor to YouSee, but this is not necessarily the case. Customers must still buy some sort of connectivity in order to access Netflix, so if they are YouSee customers, they are likely to buy Netflix as an add-on service. Customers could also downgrade to the basic cable + internet package, 459DKK and add on Netflix. In the worst case scenario, customers would simply leave YouSee and buy stand-alone DSL for about 200DKK (\$46) per month plus the monthly Netflix subscription. However, YouSee offers a number of incentives to keep its customers from churning including offering channels a la carte.

The immediate effect of Netflix entering the Danish market in October 2012 is that YouSee has offered its own OTT video service called YouBio just two months later. The offer includes free service until February 1, 2013 and thereafter $99 \mathrm{DKK} /$ month (\$17). The 20DKK premium reflects that the $25 \%$ VAT that YouBio must pay in Denmark, but Netflix invoicing from Luxembourg does not have the same rate. The effect of tax policy is addressed 
later in the document. Just one indicator of the heated competition can be observed in this screen shot from Google's search network. YouBio bids on the keyword "Netflix" to promote their service to consumers looking for Netflix.

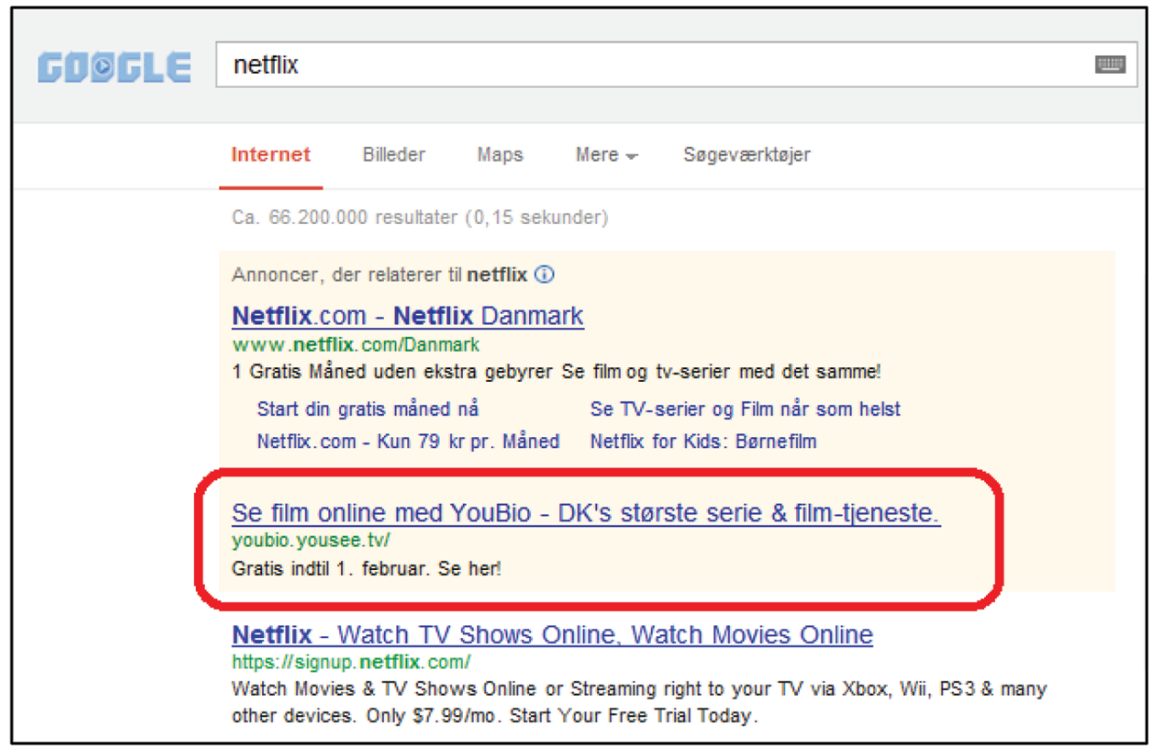

Furthermore YouSee has pulled off its Netflix offensive with humor and confidence as evidenced in the following exchange on YouSee's Facebook page with over 455 comments and 13,000 likes, more than three times the number of fans that YouSee had at the time. In the exchange customer Alexander Nikolaj Kanto writes to "break up" with YouSee and go for Netflix, what he calls the younger attractive girl. Rather than provide a last ditch attempt to win Kanto, YouSee makes a clever comeback by admitting "she" already knew the relationship was souring and points out that as the wise older woman, she makes room for all in the family, providing a range a products that suits everyone, not just the man with the mid-life crisis.

While no technology has a guaranteed future, cable TV in Denmark has certain advantages including incumbency, capacity, and price. Consumers will only upgrade to a faster network if there is a significant cost decrease, value improvement, and/or quality improvement.

The number two cable player in Denmark is Stofa with a market share of $17 \%$ for cable and $12 \%$ for the overall pay TV market. Stofa came out the 
23 October 2012

From Alexander Nikolaj Kanto

Dear YouSee:

I do not know where to start. I've struggled a bit with some things, and I am afraid that we two do not fit together anymore. I do not think we're in the same place. And now I have met someone else. She is called Netflix and we just fit well together. I'm really sorry, but I have to break up with you. There should be any more of this. But you should know that it's not you, it's me. I know there are plenty out there who would like to watch your TV channels with all the advertisements. And I may contact you again one day. Right now it may just be the two of us [Kanto and Netflix].

Have a great time.

PS: I'm sorry to do this publicly on your wall, but I have also long had the feeling that you were with someone other than me.

\section{October 2012 \\ From YouSee \\ Dear Alexander,}

I am sorry that you have found someone else. I'm not stupid, and I did well enough. It was on the way, for you have been so detached and indifferent to me recently. It was almost only when you and the guys were watching football, you'd bother me. So there was no limit to how happy you were to me - or sour if not I just was there when YOU absolutely would.

But I have not been blind to the fact that you often would rather sit behind the little stupid computer screen. So you were more interested in jumping from one more blurry and tacky home video on YouTube than me and my HD channels. And when I recently found a used Netflix coupon between sofa cushions, I knew it was over.

I'm not the first to experience a man who falls for a younger model, and probably not the last. I also know that I'm not 17 anymore, and that I've probably got a wrinkle or two. But I am not ashamed of myself. I know a lot about men and women and children. I know how to care for a family and make sure that there is room for everyone in a household - both the smallest and the oldest.

Goodbye Alexander - your Xbox may be a little wet, as I put it out in the street.

Sincerely,

YouSee

Source: https://www.facebook.com/youseedanmark/posts/374900042591894

fastest on Netflix's report of streaming speed for its service, followed closely by YouSee. Stofa is now being acquired by fiber company SE, so it possible that the deal may include an investment in improved content. 


\section{Com Hem Sweden}

Com Hem is the leading cable provider in Sweden. It was previously part of Telia, the largest telecom provider. Com Hem offers triple play of telephone, broadband, and cable with over 135 channels.

\section{Copper: Congestion Challenges with OTT Video}

Denmark, a country of 5.5 million, has $1.95 \mathrm{~m}$ residential broadband lines, some $78 \%$ of all households. Most have a capacity of at least 4Mbps xDSL, the leading network for connectivity, followed closely by cable. Naturally the addition of new services and content providers makes any network more valuable, at least in theory. Customers now have a service they did not have before. OTT video services have become so popular that operators are reluctant not to promote them.

While the advent of OTT video on copper/DSL may be exciting for subscribers, for operators of these networks, it is a cost. They don't have the same throughput as the cable networks. Operators don't earn delivery fees for the content, and they have the burden of increased traffic. Another challenge of OTT video on DSL networks is a heavier rate of bit stream, or the sequence of data through time. In practice, this property called persistency means that DSL networks which were designed for simple data with 5\% persistency, must now deliver video which has $50 \%$ or more persistency. The nature of video traffic is such that just a handful of customers can congest the entire network. In practice this means that Netflix customers on the copper network (assuming standard pricing packages) can be some of least profitable.

The challenge for operators is that the price they can charge to end users is constrained by competition (more so in Europe than the USA). Pricing by usage is also problematic as it often costly and impractical. Thus pricing is based on set bundles. So the gamer who plays data heavy video games all day pays the same as his grandma who just checks email and Facebook.

As for charging content providers such as Netflix, certain rules about network neutrality make it be difficult for operators to recover costs of network investment from the most popular websites. Film and video already account for $38 \%$ for all Danish wire line traffic, ${ }^{8}$ and in other parts of the world it is already higher than 50\%-Cable companies are better off than copper networks with regard to OTT video because they have higher throughput and offer both

\footnotetext{
${ }^{8}$ http://www.business.dk/digital/dansk-tv-krig-kan-blive-dyr
} 
connectivity and content. Of the DSL providers in Denmark, Telia, Telenor and TDC, TDC which owns YouSee, so it has the best situation of the three.

There are about 85 million households with internet access in the US. ${ }^{9}$ Netflix with 25 million subscribers can be said to be used in 1 of 3 American households. At any one time, Netflix accounts for at least $30 \%$ of all traffic on the American internet. Since its launch in Denmark in October 2012, Netflix already accounts for $15 \%$ of TDC's DSL broadband traffic. Netflix has not published the number of its customers in Denmark, but in practice this means that a handful of users are taking an increasingly large share of the network capacity. TDC actually performed faster than a number of fiber companies in the Netflix streaming report. This is likely facilitated by the fact that TDC is part of Netflix's CDN Open Connect (which will be discussed below).

Cable and copper are considered "good enough" for OTT video, even by Netflix standards. So we don't expect that consumers will make a costly upgrade to fiber to access OTT video, unless wire line quality degrades significantly.

\section{Satellite: Advantages in Hybrid Networks}

\section{Viasat: Denmark and Sweden}

Viasat is a leading satellite TV provider, serving 17 European countries. It is owned by the Swedish media conglomerate MTG and provides dozens of commercial channels across its geography (TV3, TV4, etc), channels for film, nature, sport, history, hobbies etc, and distribution rights for leading channels outside its network (BBC, Disney, CNBC, Nickelodeon etc). In practice Viasat sells its channels to other networks.

In 2007 Viasat launched Viasat On Demand, which later became Viaplay, as a complement to the existing distribution channels allowing for subscription payment or as a single on-demand streaming movies, television and sports over the internet on your computer or other device. Viaplay reduced its monthly fee to SKK79 to match Netflix and offered a new service allowing subscribers to store movies and watch them offline. Netflix expects that consumers will choose both services because they are priced so low.

Viasat is the single largest content buyer in the region with Pay 1 for Disney, NBC Universal, Sony, SF and Nordisk Film. However, Viasat's particular specialization is sports. It broadcasts the 4 European leagues for

\footnotetext{
${ }^{9}$ http://www.census.gov/hhes/computer/publications/2010.html
} 
soccer/football, European hockey, Formula One, three competitions for golf, and the American Superbowl for the region. Monthly packages begin at 455DDK (\$81).

\section{Fiber: The Swedish Standout}

The key differentiators for fiber are speed and bandwidth. In theory if one only wanted Netflix in the best possible fidelity, one would simply have fiber to the home (FTTH). In practice, fiber companies have had a difficult time getting a business case, both for the cost of laying the network itself and the fact that the current content and internet applications can be economically delivered with existing networks. In Denmark, 14 utilities companies attempted to create their own fiber networks, the logic being that fiber was like any other line to the home (water, electricity etc), but their financial returns remain dismal. Therefore it was considered a win when Waoo, a consortium of the 14 fiber companies, made a deal with Viasat to deliver content.

Fiber has fared slightly better in Norway. Altibox, a fiber country created by a Norwegian utility, has $13 \%$ of the broadband market. Over $40 \%$ of its traffic is video. After a significant initial investment, any further rollout is subject to caution. Norway is sparsely population and with just 2.2 million households served by many providers makes competing with fiber difficult. ${ }^{10}$

Sweden is the country in Europe with the highest fiber penetration, about $26 \%$ of all wire line broadband subscriptions. ${ }^{11}$ Fiber penetration is largely the result of government provision. In Netflix speed test, Swedish fiber companies took the top four positions with speeds between 2.43-2.49 Mbps with Com Hem tied for $4^{\text {th }}$ place. $^{12}$

\section{DVB-T: When a User Just Wants Old-Fashioned Television}

In recent years, classic television broadcasting moved from analog to digital. For those who only want traditional linear television, they can access the key public broadcasters via DVB-T. Digital Video Broadcasting - Terrestrial, DVB-T, is a European TV standard to transmit compressed digital audio, digital video and other data in a transport stream. Whereas traditional TV was

\footnotetext{
${ }^{10} \mathrm{http} / / /$ br0kent313ph0n3.wordpress.com/2011/10/10/fibre-lessons-from-norways-topbroadband-supplier/

${ }^{11} \mathrm{http} / / /$ www.openaxs.ch/documents/de/conference/referate/Referat-Mikael-Ek-2011.pdf

${ }^{12} \mathrm{http} / / /$ feber.se/webb/art/261237/bredbandsligan_sverige_decembe/
} 
transmitted on a single radio frequency, DVB-T splits the data and delivers it across a range of frequencies. DVB-T can work on an old-fashioned television with a receiving box. There is just one DVB-T provider in each country. Boxer has the franchise in Denmark and Sweden; in Norway, Norwegian Television. The basic package is free (subsidized through television taxes) with an opportunity to upgrade for more channels. DVB-T only solutions are frequently used by people not interested in expanded content offerings and those living in rural regions where other wireless and wire line networks may not be readily available.

\section{Summary: How Does OTT Video Impact the Network}

Different players and networks are impacted differently with OTT video. On balance, OTT video is likely to be accretive, not disruptive. Consumers, even if they buy Netflix or other another OTT video service, will still have to buy connectivity, and many consumers will buy a range of OTT video services for news and sports. Netflix only suffices for entertainment.

However some networks will be better off than others. Fiber has the highest throughput, but it is an extremely small market outside of Sweden. Wireless, though available and fast, is not the preferred means for OTT film and television. Certainly consumers watch short length YouTube videos on their phone, but when they want to watch a film or TV show, a large screen is preferred. Indeed Netflix notes that its streaming to high definition television is more than twice the amount to any other device ( $\mathrm{pc}$, table, game console, smartphone etc). ${ }^{13}$ In any case, most wireless subscribers have a wire line subscription as well.

Both copper and cable are "good enough" for OTT video, but cable is better placed than copper because of its higher throughput, content exclusivity contracts, and ability to make a competitive response to the emergence of OTT video. Copper is worst off because it has the least throughput and ability to increase price as a result of congestion created by OTT. Competitive, emerging and disruptive technologies are likely to encourage incumbent owners of different networks to cooperate to serve end users with combinations of architectures and implementations, e.g. hybrid IPTV (satellite+DSL), cable+fiber and so on.

See the following summary of the networks in response to OTT competition.

\footnotetext{
${ }^{13}$ http://www.engadget.com/2013/01/22/netflix-streaming-usage-hdtv-pc/
} 
126 R. Layton






\section{Other Impacts to the Value Chain}

\section{Lower Prices for Consumers}

In general consumers emerge as the winners from the emergence of OTT video as they now have more choice at lower prices, though this assessment needs to be tempered. OTT players like to paint a picture of the sophisticated consumer who understands the complexion of OTT offerings and equipment. The reality is that many consumers don't understand all these innovations, but simply migrate based upon their habits and what their friends and family tell them. Some of Netflix's American customers still use the DVD by mail option, even if they buy a video subscription. This is simply to say that customer behavior evolves over time and includes a range of technologies; people may still use the DVD player even when they have subscriptions for cable TV and Netflix.

\section{A La Carte Approach to Purchase Video Content}

Netflix is not an "end-all, be all" choice for consumers. It is emerging a fair choice for entertainment, but consumers will still want news and sports, and for that reason consumers are likely to choose their television in an a la carte fashion: traditional broadcasting, basic cable and a range of paid channels and OTT video depending on their tastes. Furthermore, consumers choose the content first, and by default find the distributor. For example, if one wants to see "Game of Thrones" or "True Blood", he signs up for HBO. If one is a football fan, he will likely order Viaplay, and so on. For that reason, Netflix is keen to lock up the most popular television series in its inventory. This may mean that traditional providers will have less share of wallet and viewing time than in the past.

\section{Too Much Choice Often Benefits the Incumbent}

There is some evidence from behavioral economics that too much choice actually deters customers from switching. The cost of investigating all the different services and factors becomes too high, and customers fear being worse off if they make a mistake. A number of studies show that consumers actually pay more when they switch because they don't understand all the conditions. For such reasons, many consumers simply decide to stay with their existing provider. This circle tends to keep the incumbent in a relatively good position. 


\section{Diffusion of Innovation Model}

Everett Rogers' intuitive Diffusion of Innovation model may be of some help to understand how OTT video will grow. The first movers are the small subset of the user base, the "innovators" or the $2.5 \%$. Then it is taken up by the "early adopters", $13.5 \%$. Then the technology goes main stream, with the early and late majority, comprising the bulk of the bell curve, $68 \%$ of the user base. The remaining 16\%, "the laggards", don't use the technology at all (Rogers, 1995). Netflix streaming video in the USA today is just at the tipping point of the early mainstream majority.

\section{OTT Video Driving Consumer Device and Device Software Market}

We can certainly see that the coming of OTT has stimulated innovation in the electronics industry. End users have a vast array of equipment for which to consume video content including set top boxes, tablets, smartphone, PCs, game consoles, and smart TVs (many of which are plug and play ready for OTT video). In Denmark, smart TVs account for $80 \%$ of all television purchases. OTT video is also spurring innovation in middle ware and infrastructure goods and services including CDNs, but also micro/pico cells, LTE equipment, and software for traffic management and cloud-based solutions. We also see some innovation in software applications that allow OTT video increasingly on a range of devices without add-ons such as set top boxes. In an answer to linear TV in Sweden, the app Magine allows anytime play of 16 television stations in Sweden. Even live shows can be rewound.

\section{Impact to the Content Makers and Owners}

While it is outside the scope of this article to go into depth in the content market, suffice it to say that the changes with OTT video technologies creating a world in which exclusive quality content becomes more important, content makers and owners will only gain in the process. It is possible that incumbents make drive even harder bargains to ensure their market share. At the same point, if quality content can be produced independently, for example with Netflix original series, content makers and owners may find new outlets for distribution. 


\section{Corporate Practices and Policy Issues: Netflix in the Public Domain}

\section{Netflix and the European Tax Regime}

It has long been a practice for foreign companies to set up the European headquarters in one country to avoid taxes in the others. Google, Facebook and LinkedIn all invoice their European customers from Ireland so they avoid local country taxes. The strategy, completely legal, allows Google to save some $\$ 1$ billion on taxes annually. Amazon UK which has large and established operator in the country switched its European billing to Luxembourg, allowing it to enjoy only a $3 \%$ VAT compared to its British competitors which must pay $20 \%$.

In the case of Netflix, the company invoices from Luxembourg where value added tax is just $3 \%$ or $15 \%$ depending on the service. Would Netflix invoice from the Nordic countries, it would have to add $25 \%$ or more to its monthly fee.

Naturally the EU European Commission has expressed concern that the loopholes create price distortions, and certainly the differential tax regimes do not conform to the idea of free trade or a common market.

From Ireland's perspective, the tax loophole has been defended as crucial to the country's economic growth. Indeed many tech companies have established their European headquarters in the country and have hired tens of thousands of Irish employees. Especially in the economic downturn, Ireland will protect its practice. Finance is a key industry for Luxembourg, like Switzerland, and the country considers its policies rational and profit-maximizing.

\section{Netflix and Content Delivery: A Flashpoint in Norway}

While content and scale are important part of the business model for OTT video, the role of content delivery is also important. Content delivery networks (CDNs) have emerged as a way to improve the speed and quality of data transfer. In the classic model, a CDN works in between content and network providers. The content provider pays the CDN to cache and speed delivery of its content, while the CDN pays the network operator to host its server. ISPs have also invested in their own CDNs as have some content providers. In practice, this means that Netflix users can access a copy of their favorite film from a nearby server rather than having to call all the way to Los Altos, CA. 
Netflix operates its own content delivery network called Open Connect and offers those ISPs with a licensing agreement with Netflix to peer at common internet exchanges as well as to use Netflix storage facilities. It is Netflix's operational goal to have all its traffic facilitated by its own proprietary $\mathrm{CDN}^{14}$ which can ensure it lowers costs and optimizes its technological formats. Open Connect is made of three components: servers (the CDN itself), a control core which runs in the Amazon cloud (technology which identifies the user and and his preferences) and an intelligent client which provides code to run on the user's side. This system allows Netflix a constant monitoring of user experience and helps to avoid the problem of rebuffering. ${ }^{15}$

While connecting to Netflix Open Connect in the US may be no-brainer for certain ISPs, it is not necessarily the case for all, especially for carriers that have invested in their own CDNs. Netflix has come under criticism for its practices to ISPs that decline to use Netflix Open Connect. The case of Telenor Norway with Netflix in December 2012 is a good example.

Telenor is the largest ISP in Norway and has made significant investments across Norway in its own infrastructure to serve its customers primarily with Nordic content. Telenor doesn't want to connect to Netflix's nearest exchange (Stockholm run by Swedish competitor Telia) when it has already wired the whole country (Norway is the longest European country, over 1000 miles long.). Instead Telenor offered Netflix to connect to its infrastructure. Netflix declined. The situation is a stalemate as each party has a defendable position, and neither wants to give up first. Netflix claims that Open Connect is free, but this is not true, as there are real costs for Telenor to connect to a service in another country, and furthermore, ISPs have to sign a license agreement to participate in the program. Neither party wants to give in for fear of creating a precedent.

\section{Netflix vs. Telenor Norway: David vs. Goliath?}

In its global rollout, Netflix faces important constraints such as the cost of purchasing local content and sales and marketing. Netflix has yet to break even in its international business. Because marketing costs are so high, it is understandable that Netflix looks to economize. For that reason it is smart about using public relations as a form of marketing.

Public relations is about storytelling, and Netflix has been clever to paint themselves as David in an epic battle of the upstart internet firm versus the

\footnotetext{
${ }^{14} \mathrm{http}: / / \mathrm{www}$. insidetelecom.no/telemedia/betaler-kun-for-backbone/

${ }^{15}$ Personal interview with David Fullagar, head of content delivery at Netflix, Feb 7, 2012.
} 
Goliath of telecom. As Netflix rolls out across the world, it is counting on ISPs to use Open Connect. It employs a practice of "naming and shaming" those ISPs that don't cooperate. It does this by publishing the broadband speeds that its customers experience on different networks in different countries, and uses this report as means to embarrass ISPs with slower speeds to join Open Connect. In the case of Telenor, Netflix threatened to publish the speeds in the press, showing Telenor to be the slowest network in Norway. Telenor called the practice blackmail and refused to comply. Telenor received a number of negative articles in the press as a result. ${ }^{16}$

Telenor Norway's CEO Berit Svendsen responded that they have limited complaints from customers about Netflix, and in fact, many more are positive about the experience of Netflix on Telenor's network. She adds that Netflix has placed their content in foreign data centers and expects Telenor to pay the cost to deliver it to Norway. On top of that she notes that Netflix uses a format which is not optimal for Norway's networks. Svendsen observes that Netflix has payment relationships with ISPs in the USA and other countries, so they should create a similar deal in Norway. ${ }^{17}$ See the report below which Netflix provided to the press, putting the largest Norwegian ISP Telenor in $10^{\text {th }}$ place for speeds on its wire line network.

\section{Netflix in Sweden}

Netflix was equally ebullient about Sweden as it was about Denmark, and CEO Hasting praised the Swedes ". . . both for the high broadband speeds, and that Swedes tend to be "early adopters." For example it is here that Spotify born and we have seen that consumers love is in the forefront with the latest." While the praise may play well with the public, Netflix has little patience for connectivity providers. As Chief Content Officer Ted Sarandos notes, "The established players do not want to see any change. They will offer more resistance. Others see that the internet can contribute more to the change of their brands. In Sweden we have an excellent relationship with SVT, while TV4 has not been so cooperative. 'Solsidan' is an example of a series that would fit perfectly in our service, but TV4 has been slow to come to the negotiation. We see similar examples anywhere in the world." 18

\footnotetext{
${ }^{16} \mathrm{http}: / / \mathrm{www}$. dagensit.no/article2529131.ece, http://www.dagensit.no/article2529667.ece

${ }^{17} \mathrm{http}: / /$ www.dagensit.no/article2530335.ece

${ }^{18} \mathrm{http}: / /$ www.nyteknik.se/nyheter/it_telekom/tv/article3560911.ece
} 


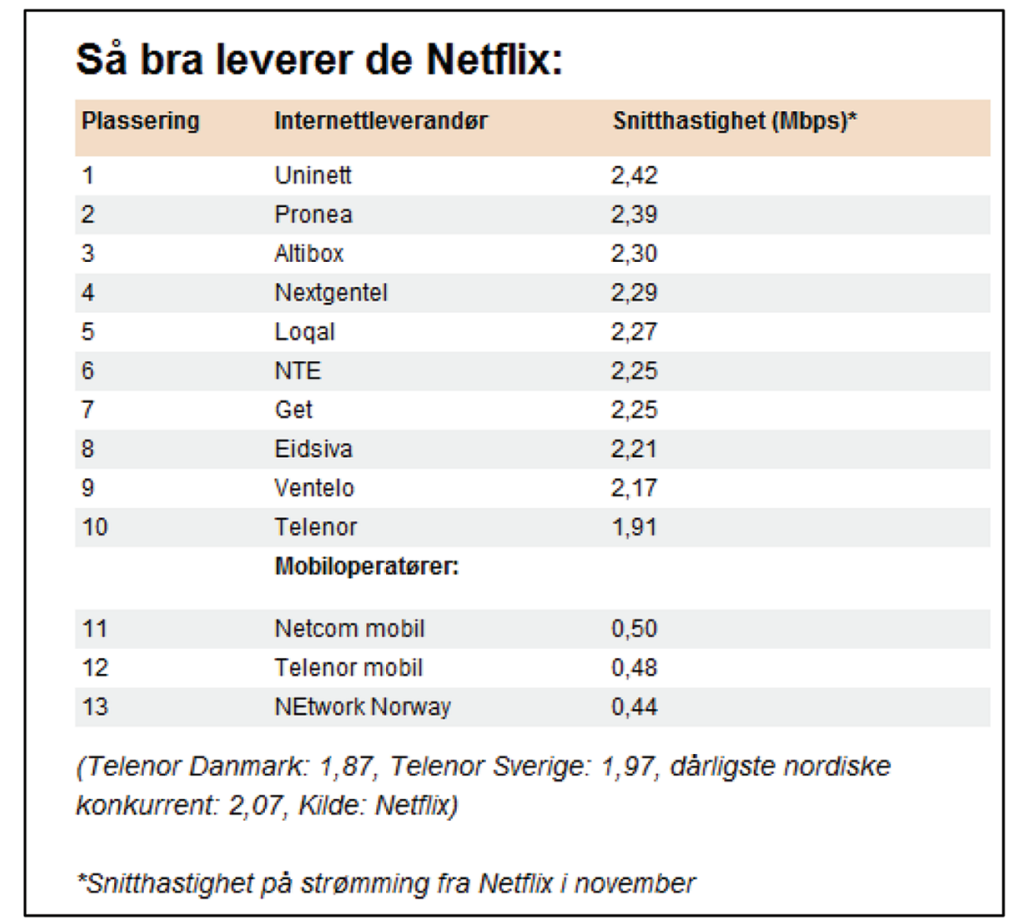

Source: Netflix, as reprinted in http://www.dagensit.no/article2529131.ece

\section{Netflix and Network Neutrality}

The growth of OTT video is certainly facilitated by content delivery networks (CDNs). These are servers placed in various locations around the world that cache and speed content. This is important service to ensure a good user experience with minimum latency.

Level3 is a CDN that has worked closely with Netflix, even helping Netflix develop its CDN Open Connect. Prior to Netflix, Level3 had a peering relationship with Comcast in which in which Level3 exchanged 2x of traffic for Comcast's 1x. When Level3 made the Netflix deal, the load from Level3 exploded to 5x, and Comcast asked Level3 for to renegotiate the peering deal. Level3 refused and sought support from the Federal Communications Commission under network neutrality principles, arguing that that they immune from being charged for content delivery.

Many will counter that caching and speeding are not violations of network neutrality, but reconfiguring routers to preference one content provider over another is. The question raised is whether the technology resides at the edge 
or the core of the internet and whether the practice violates the end to end principle. Netflix will support that Open Connect is an edge solution. Indeed, the peering locations are located in major cities where there are concentrations of customers: Atlanta, Chicago, Los Angeles, Miami, New York, San Jose, CA etc. This notion of locating the content delivery network equipment near customers is practiced widely by Akamai, the world's leading content delivery network.

Bear in mind that speeding video content is actually is considered the least profitable commodity part of the content delivery network business. The deal that Netflix struck with Level3 was priced was so low that it forced a number of CDNs out of the video streaming space. The cash flow for CDNs globally is just $\$ 2$ billion. This cash flow is same as it was about 10 years ago, but the volume of traffic that is transferred since then has exploded. This is Moore's Law at work. Indeed, the cost of caching and speeding traffic on the internet is very little compared to actual infrastructure investment of the internet itself. Telecom carriers invest some $\$ 300$ billion a year globally in wireless and wire line infrastructure.

Netflix has been one of the most outspoken supporters of network neutrality. It even created its own political action committee, Flixpac, to lobby on the issue. Netflix argues that consumers already pay for bandwidth with their subscriptions and taxing content providers for delivery is "double-charging", even though this model was a standard for traditional voice networks. Furthermore Netflix claims that it should not be responsible for the network technology decisions of operators and ISPs and that trying to contract for a delivery fee would be too difficult for a startup. In any case, Netflix defends its position saying that it constantly makes its service more efficient.

With network neutrality on its side, Netflix saves considerable sums by not having to pay for content delivery. As Chief Technology Officer Niel Hunt notes, "Distribution cost is lower than the cost of a credit card transaction, and less than five percent of the cost of the content. There is still a lot of money, but much less than what we spend on content." Even the naming of its CDN to Open Connect is a stroke of PR mastery, taking advantage of the connotation of the words which allude to the open internet and the connection via technology.

But for the leading content providers, supporting net neutrality is just a short term revenue strategy. In the long run, content providers want to ensure their content gets users in the fastest and cheapest way and if that means network innovation in the core, so be it. Microsoft and Yahoo stopped supporting net neutrality over 5 years ago. Google has relaxed its concerns of 
net neutrality on wireless networks. Netflix is already following suit as it rolls out its new Super HD service enabling video at 1080p and has struck deals with Cablevision and Google Fiber to provide it.

As we have already seen, Netflix accounts for the large and growing part of wire line network traffic. The challenge for network operators is that the traffic is consumed by a minority of their subscribers, and Netflix does not support the costs of infrastructure. Essentially all network subscribers subsidize Netflix through their internet subscriptions which pay for the fundamental infrastructure that provides a specialized service to just a fraction of homes. We might argue that price of Netflix does not include the true costs. Netflix users are probably paying too little and the rest of us paying too much. As such, Netflix is heavily dependent on informal subsidies both from ISPs investment in network as well as large pool of internet subscribers that buy internet service, whether or not they are Netflix customers. It is highly unlikely that Netflix would build its own pipe. The cost of speeding data is negligible, but building the roads themselves is the real expense. Without these informal subsidies, the business case of Netflix may not be viable.

\section{Intellectual Property Rights}

The case of Netflix highlights the issue of IPR. While digital markets are global, intellectual property regimes are national. This is a challenge for the growth of the OTT video.

Netflix has complained that pricing for film and television content is unfair and cites the example of the music industry. The OTT music business, exemplified by Spotify, offers a common set of songs and albums in all geographies. In the video business, a distributor must pay in advance for content, but in the music business, the artist is paid once the song is played.

Given Netflix's success to political action on network neutrality, it should not come as a surprise that it will lobby to reform IPR. It does suggest the possibility for the emergence of new kinds of international or at least multiterritorial licensing arrangements.

\section{How Should Network Providers Respond to OTT Video?}

On the January 23, 2013 earnings call, both CEO Netflix Reed Hastings and CFO David Wells said that operators have a "very profitable business" in delivering content. ${ }^{19}$ It's a statement that would come as a surprise to network

\footnotetext{
${ }^{19}$ http://ir.netflix.com/eventdetail.cfm?eventid=123872
} 
operators who decry that OTT video unfairly uses their network and disrupts their business model. But many industry observers have little sympathy for such concerns. They say it's time for network providers to innovate and offer their own content services.

A number of operators have attempted to become content providers but without success, notably AOL Time Warner and Orange/France Telecom. It seems the economic theory of "satisficing" explains that DSL operators, unlike cable operators, have knowledge enough only to manage networks, not to manage content, and that the two fields are distinctively different to inhibit the two competencies to flourish together.

If you consider the global average revenue per user for Netflix, about $\$ 8.5-10$, compared to a traditional telecom provider, $\$ 28$, the reward is low indeed. Even optimistic projects of the OTT video market being $\$ 37$ billion in five years provide little room and reason for large telecom operators to enter when the scale of their businesses are many times larger.

From a shareholder perspective, there are better ways to improve margins than by launching an OTT service. For example sales and marketing cost are almost twice the cost of infrastructure. Finding ways to reduce sales and marketing costs could result in better profitability that adding a new business line. As such network providers have pursued mergers where synergies made sense.

Economists frequently use a two-sided market model to describe how network providers and content providers transact. In the case of OTT video, we can extend that model to the idea of a shopping mall. In this model, the network provider is the owner of the shopping mall. He is interested to maximize the mix and quality of stores to appeal to his customer base. In general, the number of stores and the variety of stories (content providers including OTT video players) will drive traffic to the mall. However, there are certain anchor stores (or marquee websites) which customers desire above others, and any shopping mall owner would want those particular stores. In general the owner wants to ensure that any store can be easily accessed by shoppers, so he does not in practice attempt to block or lessen access to any store.

\section{Is Netflix the New Google or Facebook?}

If we look at a company such as Google, it has a bigger market share of internet search in Europe than in does for the US. Facebook has similar statistics it the market for social networking. Will an OTT video company be able to win the same advantages, or are the local country challenges and competitors 
so great that foreign platforms will find it difficult to grow? Google and Facebook have a key advantage over Netflix: they pay almost nothing for their content. Users create the content. In Google's case, it offers a local language interfaces that and search local language websites with local language advertising. Facebook is also localized. So Google and Facebook succeed for the same reasons as YouSee/YouBio and Viasat: content and scale.

While Netflix has a novel technology, it has high costs for content and little scale in new markets. This does not mean that Netflix will not grow, but that it will have to overcome some important challenges. The next 2-3 years will be key to see whether Netflix can monetize the Pay 1 window for film and whether its TV series options prove interesting to audiences.

\section{Conclusion}

Netflix represents a novel OTT video technology for the Nordic market. It has already forced some competition in the cable industry, but many cable companies are redoubling their efforts to add value to customers by lowering prices and improving content.

The debate about how to price connectivity and content delivery will continue, but a number of OTT video providers and network providers are negotiating.

The current IPR regime will certainly become an issue for debate. It is a key driver for the OTT video market, but it would have to change drastically to improve the position for Netflix. The power of the leading Hollywood studios and their strong relationships with incumbent providers should not be discounted. If anything, the major studios have seen a strengthening IPR in recent years (evidenced by length of copyright) rather than weakening.

Consumers' television consumption is changing with technology that allows them to view at their leisure and to see exactly the content they want.

\section{Further Discussion/Investigation Needed}

More analysis of fiber market

Value chain analysis

More explanation of networks and companies

More explanation of content owners, IPR, DRM 
More explanation of devices

Diagram of broadband network penetration for each country

Breakdown of $\$ 105$ million marketing spend, where profits are booked, whether Netflix takes advantage of Ireland to avoid taxes in the Nordic (waiting on Danske Bank)

\section{Biography}

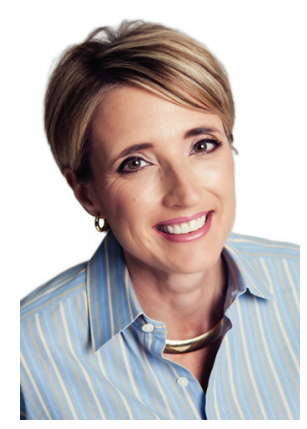

Roslyn Layton is a PhD Fellow at the Center for Communication, Media and Information Studies at Aalborg University in Denmark. An American, she is part of Denmark's Industrial PhD Program. She also serves as Vice President for Strand Consult, an independent research company studying the mobile industry. She worked in the software, IT and analytics industry in Silicon Valley and Hyderabad, India before entering academe. She holds an MBA from Rotterdam School of Management and a BA from the American University, Washington, DC. 
